\title{
The Total Bilirubin Explanatory Factors of Liver Patients
}

Rabindra Nath Das*

Department of Statistics, University of Burdwan, West Bengal, India

\section{Editorial}

Bilirubin is a product formed when our body breaks down old red blood cells. It is a substance of heme catabolism that may have potent antioxidant and cytoprotective properties [1,2]. A little amount of bilirubin in our blood is normal $(0.22-1 \mathrm{mg} / \mathrm{dl})$, but a high level may be a sign of liver disease. Therefore, total bilirubin is a biochemical liver disease marker. Literature shows that a growing body with higher bilirubin levels is negatively correlated with insulin levels, the prevalence of diabetes and cardiovascular disease [3-5]. The report examines the explanatory factors of total bilirubin. The present hypotheses are: What are the risk and protective factors of liver disease based on total bilirubin? These hypotheses are examined based on a real data set given in [6,7].

The considered real data set was obtained from the North-East of Andhra Pradesh, India. The data set contains 579 subjects with 2 attribute characters, and 9 continuous variables. It is available in the site http://archive.ics.uci.edu/ml/machine-learning-databases/00225/". The two attribute characters are sex $($ male $=0$, female $=1)$, selected field used to split the data into two sets (liver patient=1, non-liver patient=2) (CLUSTER), and their proportions are displayed in (Table 1) [8]. Note that the data set contains $71.5 \%$ liver patients, and $28.5 \%$ nonliver patients. The nine continuous variables are age, total bilirubin (TB), direct bilirubin (DB), alkaline phosphatase (ALP), alanine aminotransferase (SGPT), aspartate aminotransferase (SGOT), total proteins (TP), albumin (ALB), and albumin and globulin ratio (A/G), and their mean, standard deviation, and normal ranges are given in (Table 1) [8]. Recently, the determinants of ALP are derived in [8]. The above data set has been analyzed based on both joint generalized linear Log-normal and Gamma models $[9,10]$, as the response total bilirubin is heteroscedastic. It is observed that the joint Log-normal models give better results than Gamma fitted models, and the following results are reported based on the fitted joint Log-normal models.

The data set contains 11 explanatory variables/factors on 579 subjects. Total bilirubin (TB) is considered as the response variable, and the remaining others are considered as the explanatory variables. Based on the fitted joint Log-normal models, it is observed that sex $(\mathrm{P}=0.024)$ is inversely associated the mean $\mathrm{TB}$. Therefore, total bilirubin is lower for female patients than male. It indicates that male liver patients are at higher risk than female patients. Total bilirubin is higher at older ages $(\mathrm{P}=0.0722)$. TB increases as ALP $(\mathrm{P}<0.0001)$ or direct bilirubin $(\mathrm{DB})(\mathrm{P}<0.0001)$ increases. The interaction effect of ALP \& DB $(A L P * D B)(P<0.0001)$ is inversely associated with the mean TB. It shows that even though the marginal effects of ALP \& DB increases the mean $\mathrm{TB}$, but their joint interaction effect decreases the mean TB. TB increases as the SGPT $(\mathrm{P}=0.1146)$ increases. Note that the SGOT is not associated with the mean TB, but the joint effect of SGPT \& SGOT $\left(\mathrm{SGPT}^{\star}\right.$ SGOT $)(\mathrm{P}=0.0331)$ is negatively associated with the mean TB. Total protein $(\mathrm{TP})(\mathrm{P}=0.1111)$ is negatively associated with the mean TB. It shows that total bilirubin is higher at lower value of TP. Also the interaction effect of $\mathrm{DB} \& \mathrm{TP}\left(\mathrm{DB}^{\star} \mathrm{TP}\right)(\mathrm{P}=0.0227)$ is inversely associated with the mean TB. It shows that if the interaction effect of $\mathrm{DB} \& \mathrm{TP}$ is lower, the mean TB is higher. The mean TB increases as the albumin (ALB) $(\mathrm{P}=0.0169)$ increases. Also the albumin and globulin ratio $(A / G)(P=0.0359)$ is inversely associated with the mean $T B$. The variance of $T B$ is inversely associated with the sex $(\mathrm{P}=0.0051)$. It shows that the variance $\mathrm{TB}$ is higher for male patients than female. TB variance increases as the $\mathrm{DB}(\mathrm{P}<0.0001)$ or ALP $(\mathrm{P}=0.0327)$ increases. The summarized association of the explanatory variables/factors with total bilirubin is displayed in Table 1 .

The association of total bilirubin with the other biochemical liver disease markers, and other explanatory factors/ variables is shown above Table 1 . It is shown above that total bilirubin is positively associated with the direct bilirubin, alkaline phosphatase, alanine aminotransferase, and albumin, which are liver disease markers. So, care should be taken if one liver disease marker increases, the other should be increased. Note that their interaction effects have opposite roles. For confirmation that a patient is having liver disease, all liver disease's markers need to be tested. At older ages, care should be taken that liver diseases markers should be

\begin{tabular}{|c|c|c|c|}
\hline Response & Associated with following & $\begin{array}{c}\text { Association } \\
\text { type }\end{array}$ & P-value \\
\hline \multirow{12}{*}{$\begin{array}{l}\text { Mean Total } \\
\text { Bilirubin (TB) }\end{array}$} & Sex & negative & $P=0.0245$ \\
\hline & Age & positive & $P=0.0722$ \\
\hline & Alkaline phosphatase (ALP) & positive & $P<0.0001$ \\
\hline & Direct bilirubin (DB) & positive & $P<0.0001$ \\
\hline & $A L P * D B$ & negative & $P<0.0001$ \\
\hline & $\begin{array}{l}\text { Alamine aminotransferase } \\
\text { (SGPT) }\end{array}$ & positive & $P=0.1146$ \\
\hline & $\begin{array}{l}\text { Aspartate aminotransferase } \\
\text { (SGOT) }\end{array}$ & no & $P=0.3394$ \\
\hline & SGPT*SGOT & negative & $P=0.0331$ \\
\hline & Total protein (TP) & negative & $P=0.1111$ \\
\hline & $\mathrm{DB}^{*} \mathrm{TP}$ & negative & $P=0.0227$ \\
\hline & Albumin (ALB) & positive & $P=0.0169$ \\
\hline & Albumin and globulin ratio (A/G) & negative & $P=0.0359$ \\
\hline \multirow{3}{*}{ Variance of TB } & Sex & negative & $P=0.0051$ \\
\hline & Direct bilirubin & positive & $P<0.0001$ \\
\hline & Alkaline phosphatase (ALP) & positive & $P=0.0327$ \\
\hline
\end{tabular}

Table 1: Association of total bilirubin with different factors/ variables.

*Corresponding author: Rabindra Nath Das, Department of Statistics, The University of Burdwan, West Bengal, India, E-mail: rabin.bwn@gmail.com

Received March 29, 2018; Accepted April 02, 2018; Published April 09, 2018

Citation: Das RN (2018) The Total Bilirubin Explanatory Factors of Liver Patients. J Biomol Res Ther 7: e160. doi:10.4172/2167-7956.1000e160

Copyright: (c) 2018 Das RN. This is an open-access article distributed under the terms of the Creative Commons Attribution License, which permits unrestricted use, distribution, and reproduction in any medium, provided the original author and source are credited. 
increased. Medical practitioners take care that interaction effects of liver disease markers have opposite role than the marginal effects of the markers. As a result it is difficult to identify a patient with liver disease.

\section{Conflict of Interest}

The author confirms that this article content has no conflict of interest.

\section{References}

1. Stocker R, Yamamoto Y, McDonagh AF, Glazer AN, Ames BN (1987) Bilirubin is an antioxidant of possible physiological importance. Science 235: 1043-1046.

2. Baranano DE, Rao M, Ferris CD, Snyder SH (2002) Biliverdin reductase: a major physiologic cytoprotectant. Proc Natl Acad Sci U SA 99: 16093-16098.

3. Lin LY, Kuo HK, Hwang JJ, Lai LP, Chiang FT, et al. (2009) Serum bilirubin is inversely associated with insulin resistance and metabolic syndrome among children and adolescents. Atherosclerosis 203: 563-568.
4. Tanaka M, Fukui M, Tomiyasu K, Akabame S, Nakano K, et al. (2009) Low serum bilirubin concentration is associated with coronary artery calcification (CAC). Atherosclerosis 206: 287-291.

5. Cheriyath P, Gorrepati VS, Peters I, Nookala V, Murphy ME, et al. (2010) High Total Bilirubin as a Protective Factor for Diabetes Mellitus: An Analysis of NHANES Data From 1999-2006. J Clin Med Res 2: 201-206.

6. Ramana BV, Babu MSP, Venkateswarlu NB (2011). A critical study of selected classification algorithms for liver disease diagnosis. Intern J Database Management Systems 3: 101-114.

7. Ramana BV, Babu MSP, Venkateswarlu NB (2012) Liver classification using modified rotation forest. International Journal of Engineering Research and Development 1: 17-24.

8. Das RN, Mukherjee S, Sharma I (2018) Alkaline Phosphatase Determinants of Liver Patients. J the Pancreas 19: 1-6.

9. Lee Y, Nelder JA, Pawitan Y (2006) Generalized linear models with random effects: unified analysis via $\mathrm{H}$-likelihood. CRC Press.

10. Das RN, Lee $Y$ (2008) Log-normal versus gamma models for analyzing data from quality-improvement experiments. Quality Engineering 21: 79-87. 